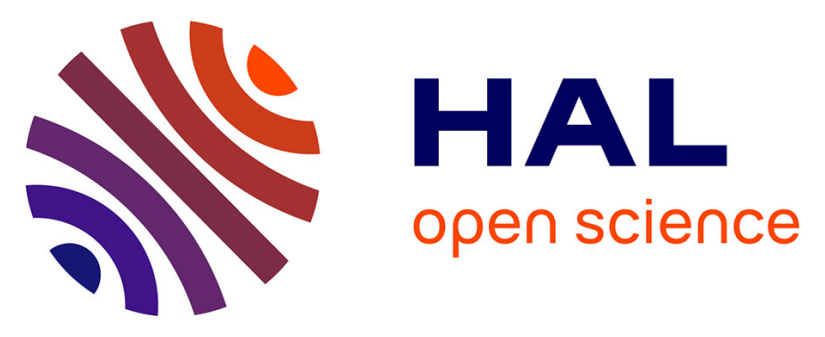

\title{
Doubly phenoxide-bridged binuclear copper(II) complexes with ono tridentate schiff base ligand: Synthesis, structural, magnetic and theoretical studies
}

Néstor Novoa, Frederic Justaud, Paul Hamon, Thierry Roisnel, Olivier Cador, Boris Le Guennic, Carolina Manzur, David Carrillo, Jean-René Hamon

\section{To cite this version:}

Néstor Novoa, Frederic Justaud, Paul Hamon, Thierry Roisnel, Olivier Cador, et al.. Doubly phenoxide-bridged binuclear copper(II) complexes with ono tridentate schiff base ligand: Synthesis, structural, magnetic and theoretical studies. Polyhedron, 2015, 86, pp.81-88. 10.1016/j.poly.2014.05.032 . hal-01067058

\section{HAL Id: hal-01067058 https://hal.science/hal-01067058}

Submitted on 22 Sep 2014

HAL is a multi-disciplinary open access archive for the deposit and dissemination of scientific research documents, whether they are published or not. The documents may come from teaching and research institutions in France or abroad, or from public or private research centers.
L'archive ouverte pluridisciplinaire HAL, est destinée au dépôt et à la diffusion de documents scientifiques de niveau recherche, publiés ou non, émanant des établissements d'enseignement et de recherche français ou étrangers, des laboratoires publics ou privés. 
Ms. Ref. No.: POLY-D-14-00195

Revised Manuscript

Doubly Phenoxide-Bridged Binuclear Copper(II) Complexes with ONO Tridentate Schiff Base Ligand: Synthesis, Structural, Magnetic and Theoretical studies

Néstor Novoa $^{\mathrm{a}, \mathrm{b}}$, Frédéric Justaud ${ }^{\mathrm{b}}$, Paul Hamon ${ }^{\mathrm{b}}$, Thierry Roisnel ${ }^{\mathrm{c}}$, Olivier Cador ${ }^{\mathrm{b}}$, Boris Le Guennic $^{\mathrm{b}}$, Carolina Manzur ${ }^{\mathrm{a}}$, David Carrillo ${ }^{\mathrm{a}}$;, Jean-René Hamon ${ }^{\mathrm{b} * *}$

a Laboratorio de Química Inorgánica, Instituto de Química, Pontificia Universidad Católica de Valparaíso, Campus Curauma, Avenida Universidad 330, Valparaíso, Chile

b UMR 6226 «Institut des Sciences Chimiques de Rennes», CNRS-Université de Rennes 1, Campus de Beaulieu, 35042 Rennes Cedex, France

c UMR 6226 «Institut des Sciences Chimiques de Rennes», CNRS-Université de Rennes 1, Centre de Diffractométrie X, Campus de Beaulieu, 35042 Rennes Cedex, France

Dedicated to Dr. Claude Lapinte for his outstanding contribution to organometallic molecular wires

- Corresponding authors. Phone: $56 \quad 3222749$ 14, E-mail address: david.carrillo@ucv.cl (D. Carrillo); Phone: 332232359 58, E-mail address: jeanrene.hamon@univ-rennes1.fr (J.-R. Hamon). 


\begin{abstract}
The tridentate ONO-donor Schiff base ligand $\mathrm{H}_{2} \mathrm{~L}$, derived from the condensation of 1-anisyl-1,3-butanedione and 2-aminophenol, was generated in situ and reacted with $\mathrm{Cu}\left(\mathrm{NO}_{3}\right)_{2} \cdot 3 \mathrm{H}_{2} \mathrm{O}$ to yield two doubly phenoxo bridged di-copper(II) complexes depending on the nitrogenous base used. $\left[\mathrm{Cu}_{2} \mathrm{~L}_{2}\right](\mathbf{1})$ is obtained in $85 \%$ and $75 \%$ yield in the presence of pyridine or 4-picoline, respectively, and $\left[(\mathrm{py}-t \mathrm{Bu})_{2} \mathrm{Cu}_{2} \mathrm{~L}_{2}\right](2)$ is isolated in $75 \%$ yield in the presence of 4-tert-butylpyridine. Compounds 1 and $\mathbf{2}$ were characterized in the solid-state by elemental analysis and FT-IR spectroscopy. Single crystal X-ray diffraction study reveals that in $\mathbf{1}$ the two four-coordinated copper atoms adopt a square planar geometry, whereas in $\mathbf{2}$ each $\mathrm{Cu}$ (II) metal ion shows a five coordinate square pyramidal (ONO,N $+\mathrm{O}$ ) geometry. In each dimer, two $\mu$-phenolic oxygen atoms bridge the two half-units forming a planar $\mathrm{Cu}_{2} \mathrm{O}_{2}$ core. EPR studies in fluid solutions indicate that the dimeric structure of $\mathbf{1}$ and $\mathbf{2}$ is destroyed upon dissolution. In the solid-state, $\mathbf{1}$ is EPR silent, whereas $\mathbf{2}$ presents an unresolved broad resonance $(\Delta \mathrm{H}$ peak-to-peak $=71.5 \mathrm{G})$ with $\mathrm{g}=2.071$ at $298 \mathrm{~K}$, along with the triplet state $(\mathrm{S}$ $=1)$ signature at $\mathrm{g}=4.181$. Variable temperature $(2-300 \mathrm{~K})$ magnetic susceptibility measurements exhibit strong antiferromagnetic interactions between the $\mathrm{Cu}(\mathrm{II})$ centers with a $\mathrm{J}$ value of $-397 \mathrm{~cm}^{-1}$ for $\mathbf{1}$, while no interaction operates between the two spins localized on $\mathrm{Cu}$ (II) metal ions in 2 . Ab initio calculations were also performed to supplement the experimental results.
\end{abstract}

Keywords: Copper(II); ONO Tridentate Schiff base ligand; magnetic properties; structure determination; EPR study; Ab initio calculation. 


\section{Introduction}

In recent years, there has been continuing interest in using bridging ligands in the synthesis of polynuclear complexes of paramagnetic transition metal ions. In particular, ligands which contain potentially bridging phenoxo, alkoxo or hydroxo oxygen and nitrogen donor atoms have been widely employed to build up multinuclear copper(II) complexes [1-5]. Such symmetrically or asymmetrically dibridged complexes with $\mu$-phenoxo, $\mu$-alkoxo or $\mu$ hydroxo di-copper(II) core have been the subject of a considerable amount of work in terms of correlating structure and magnetic properties [1,2,7-11]. Moreover, doubly phenoxo bridged binuclear $\mathrm{Cu}$ (II) complexes have also considerable interest as they provide the simplest case of magnetic interaction including only two unpaired electrons $[2,6,11,12]$. And it is now established that the major factor controlling the singlet-triplet energy gap, J, between the metal centers is the $\mathrm{Cu}-\mathrm{O}-\mathrm{Cu}$ angle [8,13-15]. Di-copper(II) derivatives are also of importance as precursors in the chemistry of supramolecular [16] and discrete molecular highnuclearity copper(II) complexes [17-21].

Diprotic Schiff bases are easily prepared by 1:1 condensation of appropriate salicylaldehyde or $\beta$-diketone reagents with appropriate amino alcohol substrates under mild conditions. Upon double deprotonation, they form a group of di-negative tridentate O,N,Odonor ligands that react readily with cupric salts to produce variable-nuclearity compounds depending on the coligand $[19,22]$. Thus, a N-donor monodentate coligand results in the formation of neutral mononuclear square planar ternary copper(II) complexes while square pyramidal $\mathrm{Cu}(\mathrm{II})$ compounds are obtained in the presence of a N-N chelate coligand [19,2327]. Moreover, the very popular bridging ligand 4,4'-bipyridine has been used also to construct homobinuclear copper(II) complexes [28], acting as a linear spacer between the mononuclear units, thus allowing the investigation of the intramolecular magnetic interaction between the magnetic centers [29].

We were interested in preparing neutral ternary mononuclear metal complexes of the type $[\mathrm{LCu}(\mathrm{II})(\mathrm{py})]$ with differently substituted di-anionic tridentate ONO Schiff base ligands $\left(\mathrm{L}^{2-}\right)$ and pyridine as ancillary ligand, as building blocks for the construction of novel selfassembled push-pull systems. However, it turned out that the synthesis using three closely related nitrogenous bases as coligand, leads to the formation of two different dimeric Schiff base complexes than those expected. Herein, we report on the synthesis, spectral and structural characterization, magnetic properties and ab initio study of both compounds formulated as $\left[\mathrm{Cu}_{2} \mathrm{~L}_{2}\right](\mathbf{1})$ and $\left[(\mathrm{py}-t \mathrm{Bu})_{2} \mathrm{Cu}_{2} \mathrm{~L}_{2}\right](\mathbf{2})$, where $\mathrm{H}_{2} \mathrm{~L}$ is the mono-condensation 
product of 1-anisyl-1,3-butanedione and 2-aminophenol (see Scheme 1). An EPR study of both complexes was also carried out.

\section{Experimental}

\subsection{Materials}

Manipulations of air-sensitive compounds were performed under Argon atmosphere using standard Schlenk techniques. Solvents were dried and distilled according to standard procedures [30]. 4-methoxyacetophenone, potassium tert-butoxide, 2-aminophenol, pyridine, 4-tert-butylpyridine, 4-picoline, Ethyl acetate (99\%) and copper(II) nitrate trihydrate were purchased from commercial sources and used without further purification. Compound 1anisyl-1,3-butanedione was synthesized according to the literature procedure [31].

\subsection{Characterization and instrumentation.}

Infrared spectra were recorded on a Perkin-Elmer, Model Spectrum One, FT-IR spectrophotometer as $\mathrm{KBr}$ disks in the 4000 to $400 \mathrm{~cm}^{-1}$ range. Elemental analyses were conducted on a Thermo-FINNIGAN Flash EA 1112 CHNS/O analyzer by the Microanalytical Service of the CRMPO at the University of Rennes 1, France. Electron paramagnetic resonance (EPR) spectra were recorded at $298 \mathrm{~K}$ with a Bruker EMX-8/2.7 (X-band) spectrometer. The temperature dependences of the magnetizations for powdered samples have been measured with a SQUID magnetometer (Quantum design MPMS-XL5) operating between 2 and $300 \mathrm{~K}$ at a constant field of $2 \mathrm{kOe}$. The experimental data have been corrected from the sample holder diamagnetism and the intrinsic diamagnetism estimated from the Pascal's tables [32]. Melting points were determined in evacuated capillaries on a Kofler Bristoline melting point apparatus and were not corrected.

\subsection{Preparations}

\subsubsection{Preparation of $\left[\left\{4-\mathrm{MeO}-\mathrm{C}_{6} \mathrm{H}_{4}-\mathrm{C}(\mathrm{O}) \mathrm{CH}=\mathrm{C}\left(\mathrm{CH}_{3}\right) \mathrm{N}-o-\mathrm{C}_{6} \mathrm{H}_{4}-\mathrm{O}\right\} \mathrm{Cu}\right]_{2}(\mathbf{1})$}

A Schlenk tube was charged with a magnetic stir bar, $200 \mathrm{mg}$ (1.04 mmol) of 1-anisyl-1,3butanedione, $114 \mathrm{mg}(1.04 \mathrm{mmol})$ of 2-aminophenol and $10 \mathrm{~mL}$ of toluene, and the mixture was refluxed for 2 hours. After cooling, a yellow solid deposited. The precipitate was filtered off and washed with a petroleum ether: diethyl ether (1:1 v:v) mixture. Then, $292 \mathrm{mg}$ (2.6 mmol) of potassium tert-butoxide and $2 \mathrm{~mL}$ of THF were added and the reaction mixture was stirred at r.t. for $20 \mathrm{~min}$, upon which time it turned dark-red. Pyridine (160 $\mu \mathrm{L}, 2.08 \mathrm{mmol})$ was then added, before dropwise addition of a solution of $\mathrm{Cu}\left(\mathrm{NO}_{3}\right)_{2} \cdot 3 \mathrm{H}_{2} \mathrm{O}(252 \mathrm{mg}, 1.04$ 
mmol) in $5 \mathrm{~mL}$ of THF. The stirring was continued overnight. The reaction was quenched with $15 \mathrm{~mL}$ of $\mathrm{EtOH}$, releasing a dark-green microcrystalline precipitate that was filtered off and washed with cold EtOH (3 x $10 \mathrm{~mL})$ and diethyl ether $(4 \times 10 \mathrm{~mL})$. The dark-green solid residue was dried under vacuum for 2 hours and dissolved in dichloromethane. The solution was subjected to slow evaporation for 5 days, affording $300 \mathrm{mg}(0.44 \mathrm{mmol}, 85 \%$ Yield $)$ of black microcrystals. A crystal from this crop was used for X-ray structure determination. M.p. 215-217 ${ }^{\circ}$ C. Anal.Calcd for $\mathrm{C}_{34} \mathrm{H}_{30} \mathrm{Cu}_{2} \mathrm{~N}_{2} \mathrm{O}_{6}\left(681.71 \mathrm{gmol}^{-1}\right)$ : C, 59.21; H, 4.38; N, 4.06.

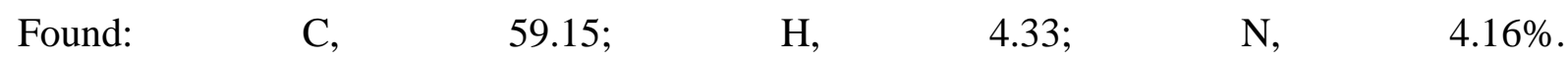
Under the same conditions, complex 1 was isolated in $75 \%$ yield when its preparation was carried out with 4-picoline (185 $\mu \mathrm{L}, 2.08 \mathrm{mmol})$ instead of pyridine.

\subsubsection{Preparation of $\left[\left\{4-\mathrm{MeO}-\mathrm{C}_{6} \mathrm{H}_{4}-\mathrm{C}(\mathrm{O}) \mathrm{CH}=\mathrm{C}\left(\mathrm{CH}_{3}\right) \mathrm{N}-o-\mathrm{C}_{6} \mathrm{H}_{4}-\mathrm{O}\right\} \mathrm{Cu}\left(\mathrm{NC}_{5} \mathrm{H}_{4}-4-\mathrm{CMe}_{3}\right)\right]_{2}$ (2)}

This complex was synthesized following a similar procedure to that described above for the preparation of 1, using in this case, $200 \mathrm{mg}(1.04 \mathrm{mmol})$ of 1-anisyl-1,3-butanedione, $114 \mathrm{mg}$ (1.04 mmol) of 2-aminophenol, $292 \mathrm{mg}(2.6 \mathrm{mmol})$ of potassium tert-butoxide, $0.44 \mathrm{~mL}$ (3.0 mmol) of 4-tert-butylpyridine and $300 \mathrm{mg}(1.24 \mathrm{mmol})$ of $\mathrm{Cu}\left(\mathrm{NO}_{3}\right)_{2} \cdot 3 \mathrm{H}_{2} \mathrm{O}$. Recrystallization by slow evaporation of a saturated $\mathrm{CH}_{2} \mathrm{Cl}_{2}$ solution yielded $506 \mathrm{mg}(75 \%)$ of a dark-green crystalline solid. A crystal from this crop was used for X-ray structure determination. M.p. 171-173 ${ }^{\circ} \mathrm{C}$. Anal. Calcd for $\mathrm{C}_{52} \mathrm{H}_{56} \mathrm{Cu}_{2} \mathrm{~N}_{4} \mathrm{O}_{6}\left(960.12\right.$ gmol $\left.^{-1}\right)$ : C, 65.05; H, 5.88; N, 5.84. Found: C, 64.74; H, 5.44; N, 5.58\%.

\subsection{X-ray crystal structure determination}

Well-shaped single crystals of $\mathbf{1}$ and $\mathbf{2}$ of suitable dimensions were coated in Paratone-N oil, mounted on a Kaptan loop and transferred to the cold gas stream of the cooling device. Intensity data were collected at $\mathrm{T}=150(2) \mathrm{K}$ on a APEXII, Bruker-AXS diffractometer, Mo$\mathrm{K} \alpha$ radiation $(\lambda=0.71073 \AA$ ), equipped with a bidimensional CCD detector and were corrected for absorption effects using multiscanned reflections. The two structures were solved by direct methods using the SIR97 program [33], and then refined with full-matrix least-square methods based on $F^{2}$ (SHELXL-97) [34] with the aid of WINGX program [35]. All non-hydrogen atoms were refined with anisotropic atomic displacement parameters. All the hydrogen atoms were placed in their geometrically idealized positions and constrained to ride on their parent atoms. A summary of the details about crystal data, collection parameters and refinement are documented in Table 1, and additional crystallographic details are in the CIF files. ORTEP views are drawn using Olex2 software [36]. 
Table 1 Crystallographic data, details of data collection and structure refinement parameters for compounds $\mathbf{1}$ and $\mathbf{2}$

\begin{tabular}{|c|c|c|}
\hline & 1 & 2 \\
\hline Empirical formula & $\mathrm{C}_{34} \mathrm{H}_{30} \mathrm{Cu}_{2} \mathrm{~N}_{2} \mathrm{O}_{6}$ & $\mathrm{C}_{52} \mathrm{H}_{56} \mathrm{Cu}_{2} \mathrm{~N}_{4} \mathrm{O}_{6}$ \\
\hline Formula mass, $\mathrm{g} \mathrm{mol}^{-1}$ & 689.68 & 960.09 \\
\hline Collection T, K & $150(2)$ & $150(2)$ \\
\hline Crystal system & Monoclinic & Triclinic \\
\hline space group & $P 2_{1} / c$ & $\mathrm{P} \overline{1}$ \\
\hline $\mathrm{a}(\AA)$ & $9.0297(2)$ & $9.4434(3)$ \\
\hline $\mathrm{b}(\AA)$ & $14.3356(4)$ & $11.3431(4)$ \\
\hline c $(\AA)$ & $11.4572(3)$ & $11.4661(4)$ \\
\hline$\alpha\left(^{\circ}\right)$ & 90 & $101.758(2)$ \\
\hline$\beta\left(^{\circ}\right)$ & $109.8300(10)$ & $109.5860(10)$ \\
\hline$\gamma\left({ }^{\circ}\right)$ & 90 & $92.739(2)$ \\
\hline$V\left(\AA^{3}\right)$ & $1395.15(6)$ & $1123.86(7)$ \\
\hline $\mathrm{Z}$ & 2 & 1 \\
\hline $\mathrm{D}_{\text {calcd }}\left(\mathrm{g} \mathrm{cm}^{-3}\right)$ & 1.642 & 1.419 \\
\hline Crystal size (mm) & $0.15 \times 0.07 \times 0.04$ & $0.41 \times 0.11 \times 0.06$ \\
\hline Crystal color & black & black \\
\hline $\mathrm{F}(000)$ & 708 & 502 \\
\hline $\operatorname{abs}$ coeff $\left(\mathrm{mm}^{-1}\right)$ & 1.577 & 1.002 \\
\hline$\theta$ range $\left(^{\circ}\right)$ & 3.41 to 27.48 & 2.96 to 27.48 \\
\hline range $h, k, 1$ & $-11 / 11,-17 / 18,-12 / 14$ & $-12 / 12,-13 / 14,-14 / 14$ \\
\hline No. total refl & 12339 & 18161 \\
\hline No. unique refl & 3183 & 5123 \\
\hline Comp. to $\theta_{\max }(\%)$ & 99.6 & 99.4 \\
\hline Max/min transmission & $0.939 / 0.856$ & $0.942 / 0.807$ \\
\hline Data/Restraints/Parameters & $3183 / 0 / 201$ & $5123 / 0 / 294$ \\
\hline Final R & $\mathrm{R}_{1}=0.0285$ & $\mathrm{R}_{1}=0.0286$ \\
\hline$[\mathrm{I}>2 \sigma(\mathrm{I})]$ & $\mathrm{wR}_{2}=0.0691$ & $\mathrm{wR}_{2}=0.0712$ \\
\hline \multirow[t]{2}{*}{$\mathrm{R}$ indices (all data) } & $\mathrm{R}_{1}=0.0378$ & $\mathrm{R}_{1}=0.0331$ \\
\hline & $\mathrm{wR}_{2}=0.0736$ & $\mathrm{wR}_{2}=0.0737$ \\
\hline Gof / $F^{2}$ & 1.016 & 1.055 \\
\hline Largest diff. Peak/hole $\left(\mathrm{e}^{-3}\right)$ & $0.430 /-0.324$ & $0.365 /-0.406$ \\
\hline
\end{tabular}




\subsection{Computational details}

DFT calculations [37] were carried out with the Amsterdam Density Functional (ADF) program [38]. The Becke approximation for exchange [39] and the Perdew expression for correlation [40] (BP) has been chosen with the TZ2P basis set [41]. The optimized geometries of both compounds $\mathbf{1}$ and $\mathbf{2}$ were characterized as true minima on the potential energy surfaces using vibrational frequency calculations.

To compute exchange couplings in $\mathbf{1}$ and $\mathbf{2}$, Complete active space self-consistent field (CASSCF) calculations [42], including two electrons in two molecular orbitals (MOs), have been performed using the MOLCAS 7.6 package [43] to generate a reference space $(\mathrm{CAS}[2,2])$. The dynamical correlation effects were then incorporated by using the dedicated difference configuration interaction (DDCI) method [44] implemented in the CASDI code [45]. With this approach, one concentrates on the differential effects rather than on the evaluation of the absolute energies. DDCI1 (i.e. CAS+S) involves one hole and one particle $(1 \mathrm{~h}, 1 \mathrm{p}, 1 \mathrm{~h} 1 \mathrm{p})$ single excitations on the full active space. DDCI2 also accounts for the two holes or two particles diexcitations ( $2 \mathrm{~h}, 2 \mathrm{p})$. Finally, the two holes/one particle ( $2 \mathrm{~h} 1 \mathrm{p})$ and one hole/two particles (1h2p) excitations are taken into account in DDCI3 (i.e. CAS+DDCI). Since the DDCI philosophy relies on the simultaneous characterization of different spin states, which share similar spatial descriptions, one has to initially determine a set of common MOs to build up the CI space. Computed $\mathrm{J}$ values strongly depend on the quality of the magnetic orbitals [46]. In the present work, one uses orbitals obtained for the lowest triplet state. Calculations have been done with $C_{i}$ symmetry on model dimers ensuing from the crystallographic data without any geometry optimization. All methyl groups have been replaced by hydrogen atoms. All atoms have been depicted with ANO-RCC type basis sets. The $\mathrm{Cu}, \mathrm{N}, \mathrm{C}$ and $\mathrm{H}$ atoms have been described with $(21 \mathrm{~s} 15 \mathrm{p} 10 \mathrm{~d} 6 \mathrm{f} 4 \mathrm{~g} 2 \mathrm{~h}) /[5 \mathrm{~s} 4 \mathrm{p} 2 \mathrm{~d} 1 \mathrm{f}]$, $(14 \mathrm{~s} 9 \mathrm{p} 4 \mathrm{~d} 3 \mathrm{f} 2 \mathrm{~g}) /[3 \mathrm{~s} 2 \mathrm{p} 1 \mathrm{~d}],(14 \mathrm{~s} 9 \mathrm{p} 4 \mathrm{~d} 3 \mathrm{f} 2 \mathrm{~g}) /[3 \mathrm{~s} 2 \mathrm{p}]$ and $(8 \mathrm{~s} 4 \mathrm{p} 3 \mathrm{~d} 1 \mathrm{f}) /[2 \mathrm{~s}]$ contractions, respectively [47]. A $(14 \mathrm{~s} 9 \mathrm{p} 4 \mathrm{~d} 3 \mathrm{f} 2 \mathrm{~g}) /[3 \mathrm{~s} 2 \mathrm{p} 1 \mathrm{~d}]$ contraction has been used for the $\mathrm{O}$ atoms directly coordinated to copper whereas other $\mathrm{O}$ atoms have been described with a $(14 \mathrm{~s} 9 \mathrm{p} 4 \mathrm{~d} 3 \mathrm{f} 2 \mathrm{~g}) /[3 \mathrm{~s} 2 \mathrm{p}]$ contraction. 


\section{Results and Discussion}

\subsection{Synthesis and characterization}

The dideprotonated ONO tridentate Schiff base ligand, [4- $\mathrm{MeO}-\mathrm{C}_{6} \mathrm{H}_{4}-$ $\left.\mathrm{C}(\mathrm{O}) \mathrm{CH}=\mathrm{C}\left(\mathrm{CH}_{3}\right) \mathrm{N}-o-\mathrm{C}_{6} \mathrm{H}_{4}-\mathrm{O}\right]^{2-}\left(\mathrm{L}^{2-}\right)$, employed in this work was generated in a two-step one-pot reaction by facile condensation of 1-anisyl-1,3-butanedione with 2-aminophenol, in 1:1 molar ratio, in refluxing toluene for 2 hours, followed by the double deprotonation of the yellow diprotic precipitate formed on cooling, with 2.5 equiv of $t \mathrm{BuO}^{-} \mathrm{K}^{+}$in THF. Pyridine based nitrogenous base $\left(4-\mathrm{NC}_{5} \mathrm{H}_{4} \mathrm{R}, \mathrm{R}=\mathrm{H}, \mathrm{CH}_{3}, \mathrm{C}\left(\mathrm{CH}_{3}\right)_{3}\right)$ was then added to the dark red reaction mixture before dropwise addition of a THF solution of the copper(II) nitrate salt. The solutions were stirred overnight to separate microcrystalline compounds. Subsequent recrystallization of the product from dichloromethane solution gave dark green crystals of the binuclear ONO Cu(II) Schiff base complexes 1 and 2, respectively (Scheme 1).

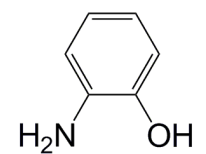

2-aminophenol

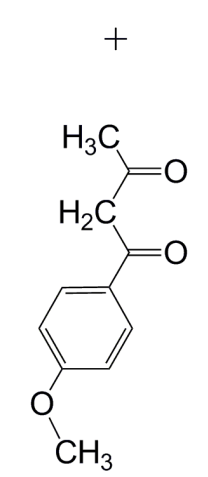

1-(4-methoxyphenyl)-

1,3-butanodione iii) Pyridine or 4-picoline iv) $\mathrm{Cu}\left(\mathrm{NO}_{3}\right)_{2} \times 3 \mathrm{H}_{2} \mathrm{O}$

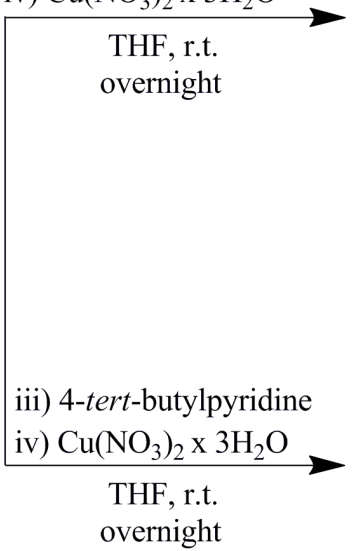

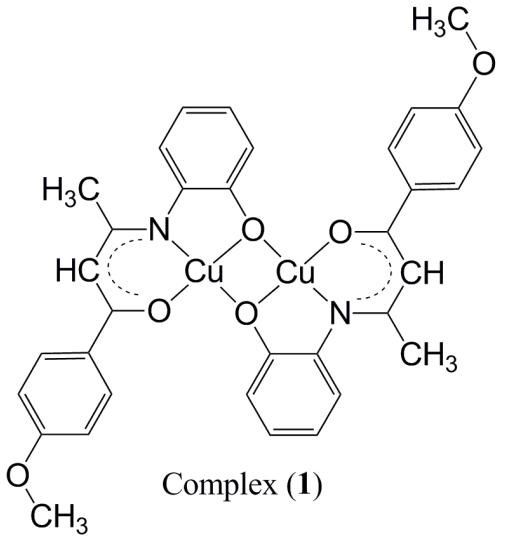

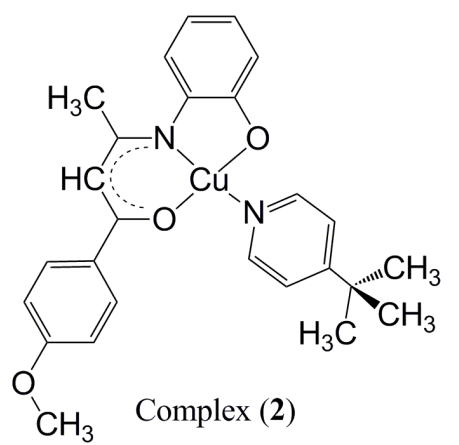

Scheme 1 Preparation of complexes $\mathbf{1}$ and $\mathbf{2}$ 
Whatever the amount of pyridine used (1 to 4 equivalents), the doubly phenoxo bridged binuclear complex 1 was always obtained and isolated in excellent yields of $80-85 \%$. The same binuclear derivative 1 was also isolated, albeit in a lower yield of 75\%, when 4picoline $\left(4-\mathrm{C}_{5} \mathrm{H}_{4} \mathrm{CH}_{3}\right)$, a more donating ligand, was used under the same conditions in place of pyridine. It is worth noting that among the nitrogenous coligands used, only the sterically more demanding 4-tert-butylpyridine does coordinate to the metal center to form the binuclear $\mathrm{Cu}$ (II) Schiff base complex 2 that is isolated in $75 \%$ yield (Scheme 1). Addition of an excess of 4-tert-butylpyridine to a THF solution of the binuclear compound $\mathbf{1}$ did not afford its mononuclear counterpart $\mathbf{2}$. The extra stability of compound $\mathbf{1}$ presumably arises from its symmetrical nature which in turn might inhibit its dissociation to generate the monomeric species $[\mathrm{Cu}(\mathrm{II}) \mathrm{L}]$.

Both compounds $\mathbf{1}$ and $\mathbf{2}$ are thermally stable, air and moisture insensitive on storage under ordinary conditions, exhibiting good solubility in common polar organic solvents but are not soluble in ethanol, diethyl ether and hydrocarbon solvents. The molecular identity and geometry of both complexes were elucidated by X-ray crystal structure determination (see below). Analysis by ESI-MS did not give the parent ions or indeed any useful information, except a prominent fragment ion observed at $M / z=345.0429$ in the mass spectrum of 1 that is assigned to the cation $\left[\mathrm{L}^{63} \mathrm{Cu}-\mathrm{H}\right]^{+}(\mathrm{M} / \mathrm{z}=345.04262)$. However, satisfactory analytical data on crystalline material demonstrates purity of both compounds (see Section 2.3).

\subsection{Infrared spectral study}

The solid-state FT-IR spectra of $\mathbf{1}$ and $\mathbf{2}$ were assigned on the basis of frequency calculations on DFT optimized geometries of 1 and 2 [37-41]. Table 2 gathers both computed and experimental major frequencies and their respective attributions, showing a good agreement between the calculated and observed spectral data. The most salient feature found in the spectra of $\mathbf{1}$ and $\mathbf{2}$ is the characteristic strong intensity bands in the ranges 1587-1466 and 1604-1584 $\mathrm{cm}^{-1}$, respectively, assigned to the $v(\mathrm{C} \cdots \mathrm{C}), v(\mathrm{C} \cdots \mathrm{N}), v(\mathrm{C} \cdots \mathrm{O})$ stretching vibrations of the Schiff base skeleton, suggesting that the imine nitrogen and carbonyl oxygen atoms coordinate to the $\mathrm{Cu}$ (II) metal ion. The weak bands observed at 3049 and $3040 \mathrm{~cm}^{-1}$ for 1 and 2 , respectively, are attributed to the aromatic $v(\mathrm{C}-\mathrm{H})$ vibrations, while the bands found at 2932 and $2830 \mathrm{~cm}^{-1}$ in the spectrum of $\mathbf{1}$ and at 2926 and $2864 \mathrm{~cm}^{-1}$ in that of $\mathbf{2}$, are characteristic of aliphatic $v(\mathrm{C}-\mathrm{H})$ vibrations. The observed medium intensity band at 1244 and $1242 \mathrm{~cm}^{-1}$ for $\mathbf{1}$ and $\mathbf{2}$, respectively, are due to the $v_{\text {asym }}$ vibration mode of the $\mathrm{CH}_{3}-\mathrm{O}$-aryl 
group. The deformation modes of the $\mathrm{C}-\mathrm{H}$ bonds in $\mathbf{1}$ and $\mathbf{2}$ show up respectively at 772 and $734 \mathrm{~cm}^{-1}$. Thus, the infrared spectral data are consistent with the structural features of both compounds (see below Section 3.3).

Table 2 Computed and experimental infrared frequencies ${ }^{\mathrm{a}}$ for compounds $\mathbf{1}$ and $\mathbf{2}$

\begin{tabular}{llll}
\hline & Computed & $\mathbf{1}^{\mathrm{b}}$ & $\mathbf{2}^{\mathrm{b}}$ \\
\hline$v(\mathrm{C}-\mathrm{H}$ aryl $)$ & $3089(\mathrm{w})$ & $3049(\mathrm{w})$ & $3040(\mathrm{w})$ \\
$v\left(\mathrm{C}-\mathrm{H},-\mathrm{OCH}_{3}\right)$ & $2992(\mathrm{w})$ & $2932(\mathrm{w})$ & $2926(\mathrm{w})$ \\
$v_{\text {sym }}\left(\mathrm{CH}_{3}\right)$ & $2949(\mathrm{w})$ & $2830(\mathrm{w})$ & $2864(\mathrm{w})$ \\
$v(\mathrm{C} \cdots \mathrm{O}), v(\mathrm{C} \cdots \mathrm{N}), v(\mathrm{C} \cdots \mathrm{C})$ & $1587(\mathrm{~s})-1466(\mathrm{~s})$ & $1581(\mathrm{~s})-1485(\mathrm{~s})$ & $1604(\mathrm{~s})-1584(\mathrm{~s})$ \\
$v_{\text {asym }}\left(\mathrm{C}-\mathrm{H}, \mathrm{C}_{6} \mathrm{H}_{4}-\mathrm{O}-\mathrm{CH}_{3}\right)$ & $1240(\mathrm{~m})$ & $1244(\mathrm{~m})$ & $1242(\mathrm{~m})$ \\
$\delta(\mathrm{C}-\mathrm{H})$ & $719(\mathrm{~m})$ & $772(\mathrm{~m})$ & $734(\mathrm{~m})$ \\
\hline
\end{tabular}

${ }^{\mathrm{a}}$ in $\mathrm{cm}^{-1} .{ }^{\mathrm{b}}$ recorded as $\mathrm{KBr}$ disk.

\subsection{Description of the molecular and crystal structures}

Perspective views of binuclear compounds $\mathbf{1}$ and 2, including the atom labeling scheme, are shown in Figs. 1 and 2, while selected bond lengths and angles are listed in Table 3. Compound 1 crystallizes in the monoclinic system with space group $\mathrm{P} 2{ }_{1} / \mathrm{c}$, while complex 2 crystallizes in the triclinic crystal system Pī space group. In both cases, the asymmetric unit consists of a neutral centrosymmetric bis( $\mu$-phenoxo)di-copper(II) complex with the two halves of the dimeric unit related by a crystallographic inversion center in the middle of the four membered $\mathrm{Cu}_{2} \mathrm{O}_{2}$ core.

In each doubly phenoxo bridged dimer, each $\mu$-phenolic oxygen atom bridges in an antisymmetric fashion two $\mathrm{Cu}$ (II) metal ions leading to a $\mathrm{Cu}_{2} \mathrm{O}_{2}$ rhombic core with two distinct bridging $\mathrm{Cu}(1)-\mathrm{O}(1)$ and $\mathrm{Cu}(1)-\mathrm{O}\left(1^{\prime}\right)$ bond lengths of 1.9357(14) and 1.9579(13) $\AA$ in 1, and 1.9247(11) and 2.445(3) $\AA$ in 2, respectively, while $\mathrm{Cu}-\mathrm{O}-\mathrm{Cu}$ bridge angles are of $102.95(6)^{\circ}$ in 1 and of $95.506(3)^{\circ}$ in 2 . In both compounds, the $\mathrm{Cu}(1)-\mathrm{O}(1)-\mathrm{Cu}\left(1^{\prime}\right)-\mathrm{O}\left(1^{\prime}\right)$ torsion angle is $0.0^{\circ}$, indicating that the $\mathrm{Cu}_{2} \mathrm{O}_{2}$ core is strictly planar. Furthermore, the intramolecular non-bonding $\mathrm{Cu}(1) \ldots \mathrm{Cu}\left(1^{\prime}\right)$ distance is 3.0462(4) in $\mathbf{1}$ and 3.253(3) $\AA$ in $\mathbf{2}$. All these bond distances and angles are in good agreement with that recently reported for analogous doubly phenoxo bridged square planar and square pyramidal $\mathrm{Cu}(\mathrm{II})$ species $[19,20,24,48,49]$. 


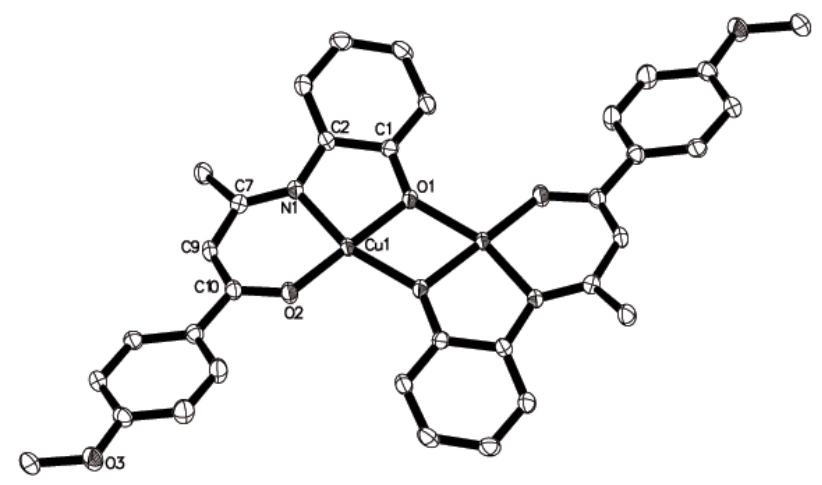

Fig. 1 Molecular structure of complex 1 showing partial atom numbering scheme. Hydrogen atoms are omitted for clarity. Thermal ellipsoids are drawn at $60 \%$ probability.

In compound $\mathbf{1}$, the dinuclear unit presents two tetracoordinated cupric ions in a slightly distorted square-planar environment (Fig. 1), with the coordination sphere formed by the deprotonated amide nitrogen atom and the carbonyl and phenoxo oxygen atoms of the acyclic Schiff base ligand, and the bridging oxygen atom of the second half-unit. The four bond lengths span the range 1.8749(14)-1.9579(13) $\AA$ (Table 3). The sum of the angles around the $\mathrm{Cu}(\mathrm{II})$ center is $359.97^{\circ}$, indicating a slightly distorted square-planar geometry around the metal atom. The diagonal angles are, indeed, found to be $176.42(6)^{\circ}[\mathrm{O}(1)-\mathrm{Cu}(1)-$ $\mathrm{O}(2)]$ and $161.35(6)^{\circ}\left[\mathrm{N}(1)-\mathrm{Cu}(1)-\mathrm{O}\left(1^{\prime}\right)\right]$. Those values deviate somewhat from idealized transoid angles of $180^{\circ}$ expected for a perfectly square-planar compound. Deviations of the coordinating $\mathrm{O}(1), \mathrm{O}\left(1^{\prime}\right), \mathrm{O}(2)$ and $\mathrm{N}(1)$ atoms around $\mathrm{Cu}(\mathrm{II})$ center from the least-square mean planes through them are 0.0224(11), -0.0198(9), 0.0166(8) and -0.0192(9) $\AA$, respectively, and that of the Copper atom from the same plane is 0.0290(6) A.

Table 3 Selected bond distances $(\AA)$ and angles $\left(^{\circ}\right)$ for compounds $\mathbf{1}$ and $\mathbf{2}$

\begin{tabular}{lll}
\hline & 1 & 2 \\
\hline $\mathrm{Cu}(1)-\mathrm{O}(1)$ & \multicolumn{1}{c}{ Bond distances } \\
$\mathrm{Cu}(1)-\mathrm{N}(1)$ & $1.9579(13)$ & $1.9247(11)$ \\
$\mathrm{Cu}(1)-\mathrm{O}(2)$ & $1.9183(16)$ & $1.9729(13)$ \\
$\mathrm{Cu}(1)-\mathrm{X}^{\mathrm{a}}$ & $1.8749(14)$ & $1.9155(11)$ \\
\hline \multicolumn{3}{c}{ Angles } \\
\hline $\mathrm{O}(1)-\mathrm{Cu}(1)-\mathrm{O}(2)$ & $1.9579(13)$ & $2.0467(13)$ \\
$\mathrm{O}(1)-\mathrm{Cu}(1)-\mathrm{N}(1)$ & $176.42(6)$ & $174.93(5)$ \\
$\mathrm{O}(2)-\mathrm{Cu}(1)-\mathrm{N}(1)$ & $84.30(6)$ & $84.60(5)$ \\
$\mathrm{N}(1)-\mathrm{Cu}(1)-\mathrm{X}^{\mathrm{a}}$ & $97.76(6)$ & $95.20(5)$ \\
$\mathrm{O}(1)-\mathrm{Cu}(1)-\mathrm{X}^{\mathrm{a}}$ & $161.35(6)$ & $162.66(5)$ \\
$\mathrm{O}(2)-\mathrm{Cu}(1)-\mathrm{X}^{\mathrm{a}}$ & $77.05(6)$ & $90.86(5)$ \\
\hline${ }^{\mathrm{a}} \mathrm{X}=\mathrm{O}(1)^{\# 1}$ for $\mathbf{1}, \mathrm{X}=\mathrm{n}(2)$ for 2; \#1 & Symmetry transformations used to generate equivalent atoms: $-\mathrm{x}+1,-\mathrm{y},-\mathrm{z}+1$.
\end{tabular}


By contrast, the binuclear unit of 2 exhibits two pentacoordinated $\mathrm{Cu}$ (II) centers in a square pyramidal (4+1) coordination geometry (Fig. 2). The basal plane consists of the same tridentate ONO- donor set of atoms as in $\mathbf{1}$ and the nitrogen atom of the monodentate 4-tertbutylpyridine, while the apical site is occupied by the phenoxido oxygen atom of another ONO-tridentate dianion that is basal to the second copper(II) metal ion of the dimer. The copper atom is deviated by $0.1022 \AA$ from the basal plane due to the formation of the axial bond. The bond distances of the donor atoms of the tridentate Schiff base ligand to the central metal atom are in the range $1.9155(11)$ to $1.9729(13) \AA$, and are typical for $\mathrm{Cu}(\mathrm{II})$ complexes $[19,20,23-27,50,51]$. The $\mathrm{Cu}(\mathrm{II})-\mathrm{N}_{\mathrm{py}}$ bond distance of $2.0467(13) \AA$ is slightly longer than those observed in related ternary square-planar $\mathrm{Cu}$ (II) complexes (1.90-1.96 ^) [23-27]. Such a lengthening may explain an easy dissociation of less donating and less sterically demanding monodentate $\mathrm{N}$-donor ligand leading to the formation of square planar dimeric complex $\mathbf{1}$, as observed here with pyridine and 4-picoline. Obviously, the $\mathrm{Cu}(1)-\mathrm{O}\left(1^{\prime}\right)$ axial bond length $(2.445(3) \AA)$ is much longer than the equatorial distances which may be ascribed to JahnTeller distortion. The Addison parameter $(\tau)$ [52] which is an index of distortion from the square-pyramidal to the trigonal-bipyramidal geometry is calculated to be 0.072 , indicating that the pentacoordinated geometry is very little distorted from a perfectly square pyramid $(\tau$ $=0$ ). The dihedral angle between the bridging $\mathrm{Cu}_{2} \mathrm{O}_{2}$ plane and the mean basal plane of the copper square pyramid is $80.713(4)^{\circ}$.

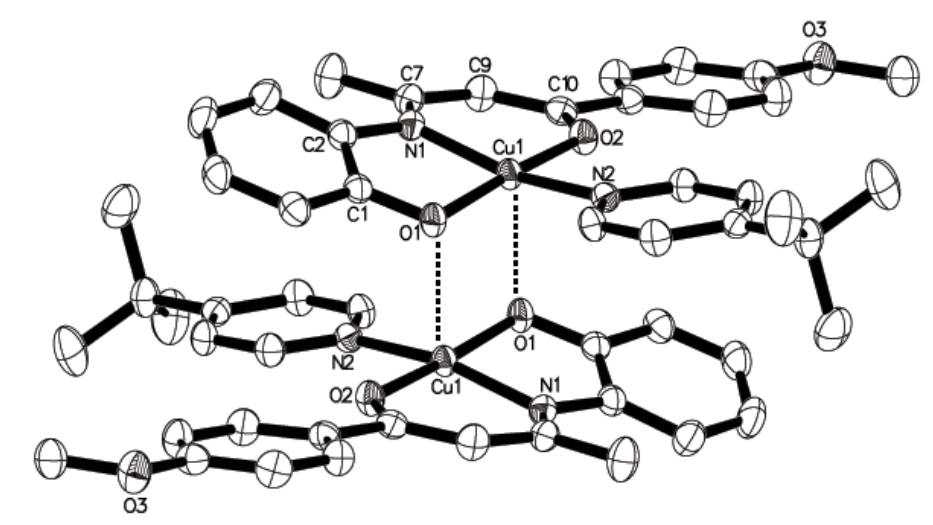

Fig. 2 Molecular structure of complex 2 showing partial atom numbering scheme and apical short contact $\mathrm{Cu}-\mathrm{O}$ interactions in dashed-line. Hydrogen atoms are omitted for clarity. Thermal ellipsoids are drawn at $60 \%$ probability. 
In both complexes, the fused five- and six-membered heterometallacycles formed upon the Schiff base condensation of anisoylacetone with aminophenol and subsequent chelation of the $\mathrm{Cu}(\mathrm{II})$ ion, are essentially co-planar. Moreover, the six-membered metallacycle is also co-planar with the anisyl substituent with dihedral angles of 3.202(3) and $0.868(2)^{\circ}$ in 1 and 2 , respectively, and of $25.60(3)^{\circ}$ with the 4-tert-butylpyridine ligand in 2 . In addition, interatomic distances and angles (Tables 3 and 4) are indicative of substantial $\pi$ delocalization of the electron density through the chelate rings.

\subsection{EPR spectroscopy}

The X-band EPR spectra of compounds $\mathbf{1}$ and $\mathbf{2}$ have been recorded in fluid solutions and as powdered samples at room temperature $(298 \mathrm{~K})$. The spectra of compound $\mathbf{1}$, recorded on a polycrystalline powder, do not show any EPR signal. In contrast, EPR spectrum of 2 , obtained in the polycrystalline state at room temperature (Fig. 3), exhibits unresolved broadband resonances, due to exchange coupling between the copper(II) ions, at $\mathrm{g}=2.071$ with a $\Delta \mathrm{H}$ peak-to-peak values of $71.5 \mathrm{G}$. Moreover, the spectrum showed a weak $\Delta \mathrm{M}_{\mathrm{S}}= \pm 2$ half field transition (Fig. 3, insert) at $\mathrm{g}=4.181$, thus giving unequivocal proof of the existence of the triplet state $(\mathrm{S}=1)$ in the solid.

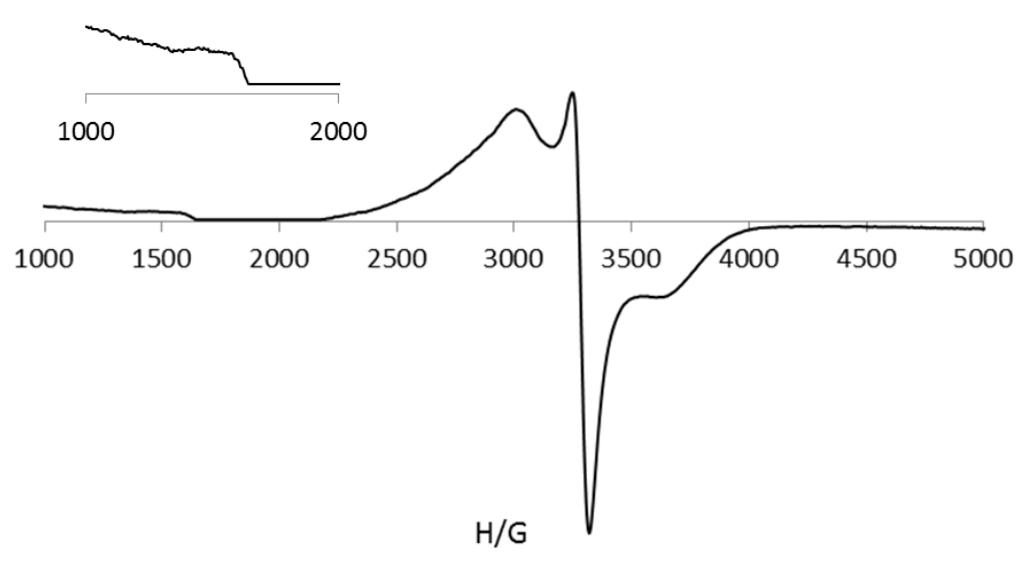

Fig. 3 Experimental EPR spectrum of complex 2 recorded in the solid state at $298 \mathrm{~K}$ with an expansion of the half-field region.

The fluid spectrum of compound $\mathbf{1}$ dissolved in pure pyridine, is typical of mononuclear $\mathrm{Cu}(\mathrm{II})$ centers and shows a well-resolved hyperfine structure with isotropic $\mathrm{g}$ 
value of 2.115 with hyperfine coupling constants $\mathrm{A}_{\mathrm{Cu}}$ of $76 \mathrm{G}$. This observation suggests that, after dissolution, the dimeric structure of $\mathbf{1}$ is destroyed, as noticed for other polynuclear $\mathrm{Cu}(\mathrm{II})$ compounds $[5 \mathrm{~b}, 54]$.

On the other hand, at $298 \mathrm{~K}$ in $\mathrm{CH}_{2} \mathrm{Cl}_{2}$ :1,2- $\mathrm{C}_{2} \mathrm{H}_{4} \mathrm{Cl}_{2}$ (1:1 v:v) solution (Fig. 4), the spectrum of compound 2 exhibits partially resolved superhyperfine structure $\left(5\right.$ lines, $A_{N}=$ $11.5 \mathrm{G}$ ) superimposed on the quartet hyperfine structure centerd at $\mathrm{g}_{\text {iso }}=2.101$ with hyperfine coupling $\mathrm{A}_{\mathrm{Cu}}$ value of $90 \mathrm{G}$. Those data are consistent with a mononuclear copper(II) species $(\mathrm{S}=1 / 2)$, with the $\mathrm{Cu}(\mathrm{II})$ ion in a slightly distorted square planar or square pyramidal coordination environment $[26,50,53,55]$.

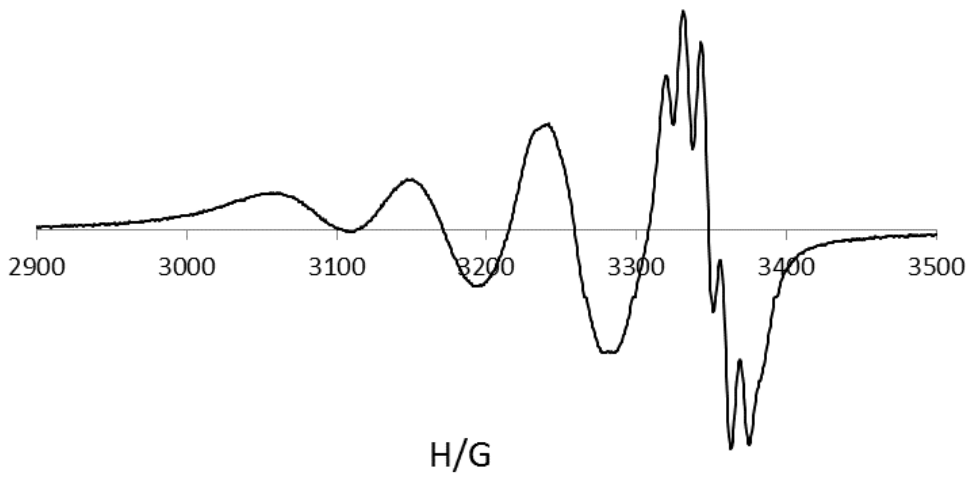

Fig. 4 X-band EPR spectrum of 2 recorded in $\mathrm{CH}_{2} \mathrm{Cl}_{2}$ : $1,2-\mathrm{C}_{2} \mathrm{H}_{4} \mathrm{Cl}_{2}(1: 1 \mathrm{v}$ :v) mixture at 298 K.

\subsection{Magnetic properties}

The magnetic properties of compounds $\mathbf{1}$ and $\mathbf{2}$ have been measured from room temperature to $2 \mathrm{~K}$ using a constant applied field of $2 \mathrm{kOe}$. On cooling a powdered sample of $1 \chi_{M} \mathrm{~T}$ ( $\chi_{M}$ the magnetic molar susceptibility and $\mathrm{T}$ the temperature in Kelvin) decreases continuously from $0.375 \mathrm{~cm}^{3} \mathrm{~K} \mathrm{~mol}^{-1}$ down to almost zero $\left(0.02 \mathrm{~cm}^{3} \mathrm{~K} \mathrm{~mol}^{-1}\right)$. This is a clear indication that very strong antiferromagnetic interaction operates between the two spins. The experimental temperature dependence of $\chi_{M} T$ of two spins interacting through the Heisenberg-Dirac-van Vleck Hamiltonian $\left(\mathrm{H}=-\mathrm{J} \boldsymbol{S}_{\boldsymbol{A}} \cdot \boldsymbol{S}_{\boldsymbol{B}}\right)$ is reproduced by a slightly modified Bleaney-Bowers equation $[11,56]$ : 


$$
\chi_{M} T=(1-x) \frac{2 N g^{2} \beta^{2}}{k} \frac{1}{3+\exp \left(-\frac{J}{k T}\right)}+x \frac{2 N g^{2} \beta^{2}}{3 k} S(S+1)
$$

$N, \beta, g$, and $k$ represent the Avogadro number, the Bohr magneton, the Boltzman constant and the Zeeman factor respectively, while $\mathrm{x}$ represents the fraction of paramagnetic impurities in the sample. The best agreement between experiment and theory (Fig. 5) is obtained with $g=2.15$ and $J=-397 \mathrm{~cm}^{-1}$. Such a strong antiferromagnetic spin-coupling involving two $\mathrm{dx}^{2}-\mathrm{y}^{2}$ orbitals of the metal centers could be expected owing to magnetic interactions mediated by equatorial-equatorial bridging ligands with a $\mathrm{Cu}-\mathrm{O}-\mathrm{Cu}$ angle of $102.95(6)^{\circ}[8,13-15]$, agreeing well with those reported for other analogous compounds $[19,20]$.

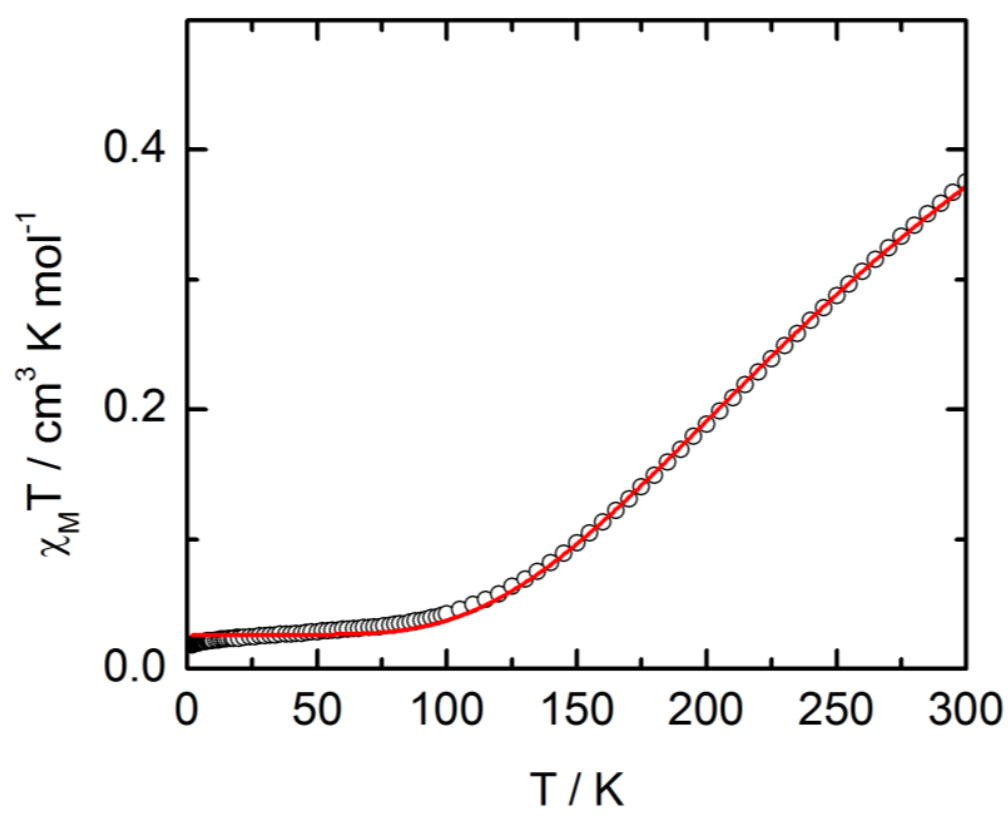

Fig. 5 Temperature dependence of $\chi_{M} T$ for compound 1 (empty circles) with the best-fitted curve (full red line).

Compound 2 behaves differently from 1. Indeed, $\chi_{M} T\left(\chi_{M}\right.$ the magnetic molar susceptibility and $\mathrm{T}$ the temperature in Kelvin) for compound 2 is constant and equal to $0.87 \mathrm{~cm}^{3} \mathrm{~K} \mathrm{~mol}^{-1}$ (Fig. 6) in the whole temperature range which witnesses that no interaction operates between the two spins localized on $\mathrm{Cu}$ (II) metal ions. With this Curie constant we can determine the average Zeeman value $\mathrm{g}=2.152$ per $\mathrm{Cu}$ (II) center. The simulated Brillouin curve for two uncoupled $\mathrm{Cu}$ (II) perfectly reproduces the field variation of the magnetization at $2 \mathrm{~K}$ (inset of 
Fig. 5). Compound 2 shows a slightly distorted square-pyramidal geometry, thus the magnetic interactions that are mediated by apical-equatorial bridges are expected to be negligible as the $\mathrm{dx}^{2}-\mathrm{y}^{2}$ and $\mathrm{dz}^{2}$ orbitals of the $\mathrm{Cu}(\mathrm{II})$ centers are orthogonal to each other (see below Section 3.6), and the axial $\mathrm{Cu}-\mathrm{O}$ bond is significantly longer $(0.5203 \AA)$ than the equatorial ones.

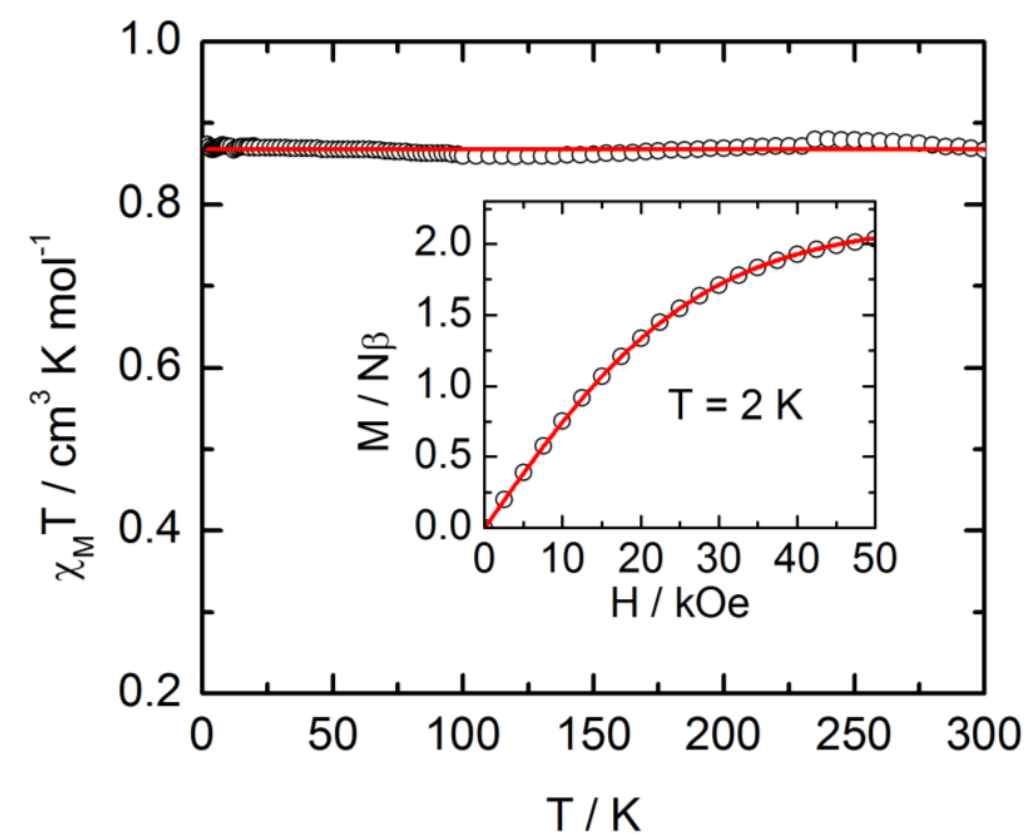

Fig. 6 Temperature dependence of $\chi_{M} T$ for compound 2 with the best fitted curve with a Curie law (full line). Inset: field variation of the magnetization for compound 2 at $2 \mathrm{~K}$ with the best fitted curve with a Brillouin law (full line).

\subsection{Theoretical investigations}

To complete magnetic measurements, ab initio calculations of the magnetic interactions in $\mathbf{1}$ and $\mathbf{2}$ have been performed at the CAS[2,2]SCF/DDCI level (see computational details). Such a computational approach usually gives excellent agreement with respect to experimental findings [57], even for through-space interactions such as in 2 [58]. Of course, DFT (within the broken symmetry (BS) approximation) could have been used instead of CASSCF/DDCI approach [59]. However, major drawbacks, among them the spin contamination of the BS wavefunction and the choice of the exchange-correlation functional, explain the present choice of wavefunction-based multireference approaches. Results are gathered in Table 4 and the magnetic orbitals of $\mathbf{1}$ are given in Fig. 7. At the best level of calculation, i.e. CAS+DDCI, the strong antiferromagnetic behaviour of $\mathbf{1}$ is recovered whereas no interaction is calculated in the case of $\mathbf{2}$ due to a poor through-space overlap 
between the magnetic orbitals. Both results confirm the experimental data although in the case of 1, slight discrepancy remains between the measured and calculated exchange couplings.

Table 4 Calculated exchange coupling constant $J\left(\mathrm{~cm}^{-1}\right)$ in model complexes of $\mathbf{1}$ and 2

\begin{tabular}{|ccc|}
\hline & $\mathbf{1}$ & $\mathbf{2}$ \\
\hline \hline CAS[2,2]SCF & -40.0 & 0.5 \\
CAS & -27.5 & 0.5 \\
CAS+S & -115.3 & -0.6 \\
CAS+DDCl & -256.0 & 3.1 \\
\hline
\end{tabular}

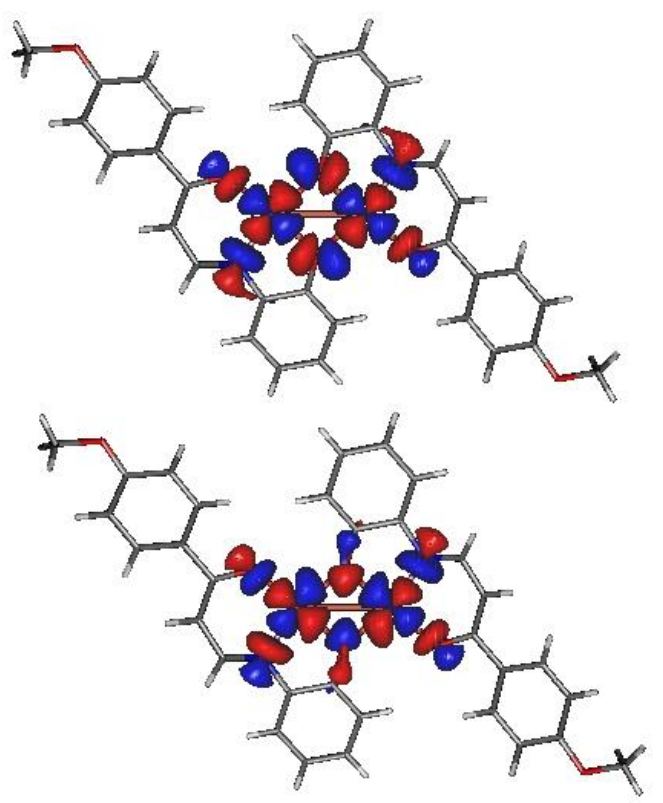

Fig. 7 Magnetic MOs extracted from a CAS[2,2]SCF calculation over the triplet state.

\section{Conclusion}

In this report, we have shown that treatment of the dianionic ONO-tridentate ligand derived from the Schiff base condensation of 1-anisyl-1,3-butanedione and 2-aminophenol, with $\mathrm{Cu}$ (II) ions leads to the dinuclear complex $\mathbf{1}$ when the reaction is carried out in the presence of pyridine or 4-picoline, while the same reaction carried out in the presence of 4tert-butylpiridine results in the formation of the binuclear species $\mathbf{2}$. Both compounds have been authenticated by single crystal X-ray diffraction analysis that showed that dimeric complex 1 presents two tetracoordinated $\mathrm{Cu}(\mathrm{II})$ centers in a square planar environment and that dimer 2 exhibits two pentacoordinated $\mathrm{Cu}(\mathrm{II})$ centers with a square pyramidal coordination sphere. The two halves of the dimeric unit are related through a planar $\mathrm{Cu}_{2} \mathrm{O}_{2}$ 
rhombic core in both cases. EPR study in fluid solutions indicates that the dimeric structure of $\mathbf{1}$ and $\mathbf{2}$ is destroyed upon dissolution. In the solid-state, $\mathbf{1}$ is EPR silent whereas both $\triangle \mathrm{MS}=$ \pm 1 and $\Delta \mathrm{MS}= \pm 2$ transitions are observed for 2 . The variable temperature magnetic measurements reveal that dimer $\mathbf{1}$ exhibits a strong antiferromagnetic interaction due to the coplanar disposition of the $\mathrm{Cu}$ (II) metal ions and acute $\mathrm{Cu}-\mathrm{O}-\mathrm{Cu}$ angle $\left(102^{\circ}\right)$, whereas dimer 2 shows negligible antiferromagnetic coupling caused by the basal-apical phenoxido oxygen bridging mode. The magnetic findings have been corroborated by theoretical Ab initio calculations.

\section{Appendix A. Supplementary data}

\section{Acknowledgments}

The authors thank Drs. M. Fuentealba (PUC Valparaíso) and P. Jehan (CRMPO, Rennes) for helpful assistance and discussion with DFT calculations and HRMS measurements, respectively. This research has been performed as part of the Chilean-French International Associated Laboratory for "Inorganic Functional Materials" (LIAMIF-CNRS $\left.N^{\circ} 836\right)$. Financial support from the Fondo Nacional de Desarrollo Científico y Tecnológico [FONDECYT (Chile), grant no. 1130105 (D.C., C.M. and M. F.)], the Vicerrectoría de Investigación y Estudios Avanzados, Pontificia Universidad Católica de Valparaíso, Chile (D.C., C.M. and M. F.), the CNRS and the Université de Rennes 1 is gratefully acknowledged. N.N. Thanks the CONICYT (Chile) and BECAS-CHILE for support of a graduate and Joint Supervision Scholarship (PUCV / UR1) and the Rennes Metropole for the 2013 scholarship awarded doctoral internship.

\section{References}

[1] D. Venegas-Yazigi, D. Aravena, E. Spodine, E. Ruiz, S. Alvarez, Coord. Chem. Rev. 254 (2010) 2086.

[2] E. Ruiz, S. Alvarez, A. Rodríguez-Fortea, P. Alemany, Y. Pouillon, C. Massobrio, in: J.S. Miller, M. Drillon (Eds.), Electronic Structure and Magnetic Behavior in Polynuclear Transition-Metal Compounds, vol. 2, Wiley-VCH, Weinheim, 2001, p. 227.

[3] S. Anbu, M. Kandaswamy, Polyhedron 30 (2011) 123. 
[4] R. Vafazadeh, B. Khaledi, A.C. Willis, M. Namazian, Polyhedron 30 (2011) 1815.

[5] (a) A. Jana, S. Mohanta, Inorg. Chim. Acta, 405, (2013) 265; (b) S. Saha, A. Sasmal, C. R. Choudhury, C. J. Gómez-Garcia, E. Garribba, S. Mitra, Polyhedron 69 (2014) 262.

[6] D. Gatteschi, O. Kahn, R.D. Willet, Magnetostructural Correlations in Exchange Coupled Systems, Reidel, Dordrecht, 1984.

[7] V.H. Crawford, H.W. Richardson, J.R. Wasson, D.J. Hodgson, W.E. Hatfield, Inorg. Chem. 15 (1976) 2107.

[8] L. Merz, W. Haase, J. Chem. Soc., Dalton Trans. (1980) 1594.

[9] T.N. Doman, D.E. Williams, J.F. Banks, R.M. Buchanan, H.-R. Chang, R.J. Webb, D.N. Hendrickson, Inorg. Chem. 29 (1990) 1058.

[10] G. Dutta, R. K. Debnath, A. Kalita, P. Kumar, M. Sarma, R. B. Shankar, B. Mondal, Polyhedron 30 (2011) 293.

[11] O. Kahn, Molecular Magnetism, VCH Publishers, New York, 1993.

[12] J.-P. Launay, M. Verdaguer, Electrons in Molecules: From Basic Principles to Molecular Electronics, 1st Edn, OXFORD University Press, Oxford, UK, 2014, Chapter 2, p. 145 .

[13] L.K. Thompson, S.K. Mandal, S.S. Tandon, J.N. Bridson, M.K. Park, Inorg. Chem. 35 (1996) 3117.

[14] E. Ruiz, P. Alemany, S. Alvarez, J. Cano, Inorg. Chem. 36 (1997) 3683.

[15] E. Safaei, A. Wojtczak, E. Bill, H. Hamidi, Polyhedron 29 (2010) 2769.

[16] S. Gupta, A. Mukherjee, M. Nethaji, A. R. Chakravarty, Polyhedron 24 (2005) 1922. 
[17] A. Mukherjee, R. Raghunathan, M.K. Saha, M. Nethaji, S. Ramasesha, A.R. Chakravarty, Chem.-Eur. J. 11 (2005) 3087.

[18] S. G. Naik, A. Mukherjee, R. Raghunathan, M. Nethaji, S. Ramasesha, A. R. Chakravarty, Polyhedron 25 (2006) 2135.

[19] P. Bhowmik, N. Aliaga-Alcalde, V. Gómez, M. Corbella, S. Chattopadhyay, Polyhedron 49 (2013) 269.

[20] N.E. Borisova, A. Kostin, T.V. Magdesieva, M.D. Reshetova, O. Nikitin, V. ParedesGarcía, M.T. Garland, P. Hermosilla-Ibáñez, W. Cañon-Mancisidor, A. Rodionov, D. Venegas-Yazigi, E. Spodine, New J. Chem. 38 (2014) 709.

[21] S. Khanra, T. Weyhermüller, P. Chaudhuri, Dalton Trans. (2009) 3847.

[22] C.R. Bhattacharjee, P. Goswami, H.a.R. Pramanik, P.C. Paul, P. Mondal, Spectrochim. Acta A78 (2011) 1408.

[23] R.N. Patel, V.L.N. Gundla, D.K. Patel, Polyhedron 27 (2008) 1054.

[24] R. Vafazadeh, R. Esteghamat-Panah, A. C. Willis, A. F. Hill, Polyhedron 48 (2012) 51.

[25] P.A.N. Reddy, M. Nethaji, A.R. Chakravarty, Inorg. Chim. Acta 337 (2002) 450.

[26] A. Garc1'a-Raso, J. J. Fiol, B. Adrover, P. Tauler, A. Pons, I. Mata, E. Espinosa, E. Molins, Polyhedron 22 (2003) 3255.

[27] R.N. Patel, N. Singh, V.L.N. Gundla, Polyhedron 25 (2006) 3312.

[28] C. Biswas, S. Chattopadhyay, M.G.B. Drew, A. Ghosh, Polyhedron 26 (2007) 4411.

[29] V. Tudor, V. Kravtsov, M. Julve, F. Lloret, Y.A. Simonov, J. Lipkowski, V. Buculei, M. Andruh, Polyhedron 20 (2001) 3033. 
[30] W.L.F. Armarego, C.L.L. Chai, Purification of Laboratory Chemicals, Fifth ed., Butterworth-Heinemann, 2003.

[31] V.V. Popic, S.M. Korneev, V.A. Nikolaev, I.K. Korobitsyna, Synthesis (1991) 195.

[32] P. Pascal, Ann. Chim. Phys. 19 (1910) 5.

[33] A. Altomare, M.C. Burla, M. Camalli, G. Cascarano, C. Giacovazzo, A. Guagliardi, A.G.G. Moliterni, G. Polidori, R. Spagna, J. Appl. Crystallogr. 32 (1999) 115.

[34] G.M. Sheldrick, Acta Crystallogr. A64 (2008) 112.

[35] L.J. Farrugia, J. Appl. Crystallogr. 45 (2012) 839.

[36] O.V. Dolomanov, L.J. Bourhis, R.J. Gildea, J.A.K. Howard, H. Puschmann, J. Appl. Crystallogr. 42 (2009) 339.

[37] E.J. Baerends, D.E. Ellis, P. Ros, Chem. Phys. 2 (1973) 41.

[38] (a) G.T. Velde, F.M. Bickelhaupt, E.J. Baerends, C.F. Guerra, S.J.A. van Gisbergen, J.G. Snijders, T. Ziegler, J.Comput. Chem. 22 (2001) 931; (b) C.F.; Guerra, J.G. Snijders, E.J. Baerends, Theor. Chem. Acc. 99 (1998) 391; (c) ADF2012.01, SCM, Theoretical Chemistry, Vrije Universiteit, Amsterdam, The Netherlands, http://www.scm.com.

[39] A. Becke, Phys. Rev. A 38 (1998) 3098.

[40] J.P. Perdew, Phys. Rev. B 33 (1986) 8822.

[41] E. Van Lenthe, E.J. Baerends, J. Comput. Chem. 24 (2003) 1142.

[42] B.O. Roos, Adv. Chem. Phys. 69 (1987) 399. 
[43] F. Aquilante, L. DeVico, N. Ferre, G. Ghigo, P.A. Malmqvist, P. Neogrady, T. Bondo Pedersen, M. Pitonak, M. Reiher, B.O. Roos, L. Serrano-Andres, M. Urban, V. Veryazov, R. Lindh, J. Comput. Chem. 31 (2010) 224.

[44] (a) J. Miralles, J.P. Daudey, R. Caballol, Chem. Phys. Lett. 198 (1992) 555; (b) J. Miralles, O. Castell, R. Caballol, J.P. Malrieu, Chem. Phys. 172 (1993) 33.

[45] N. Ben Amor, D. Maynau, Chem. Phys. Lett. 286 (1998) 211.

[46] (a) C. Angeli, C.J. Calzado, J. Chem. Phys. 137 (2012) 034104; (b) N. Suaud, R. Ruamps, N. Guihery, J.P. Malrieu, J. Chem. Theory Comput. 8 (2012) 4127.

[47] (a) B.O. Roos, R. Lindh, P.A. Malmqvist, V. Veryazov, P.O. Widmark, J. Phys. Chem. A 108 (2004) 2851; (b) B.O. Roos, R. Lindh, P.A. Malmqvist, V. Veryazov, P.O. Widmark, J. Phys. Chem. A 109 (2005) 6575.

[48] A. Mukherjee, M.K. Saha, M. Nethaji, A.R. Chakravarty, Polyhedron 23 (2004) 2177.

[49] A. Jakob, C.C. Joubert, T. Rüffer, J.C. Swarts, H. Lang, Inorg. Chim. Acta 411 (2014) 48.

[50] R.N. Patel, S.P. Rawat, M. Choudhary, V.P. Sondhiya, D.K. Patel, K.K. Shukla, D.K. Patel, Y. Singh, R. Pandey, Inorg. Chim. Acta 392 (2012) 283.

[51] Y. Yahsi, H. Kara, Inorg. Chim. Acta 397 (2013) 110.

[52] A.W. Addison, T.N. Rao, J. Reedijk, J. van Rijn, G.C. Verschoor, J. Chem. Soc., Dalton Trans. (1984) 1349.

[53] B. Sarkar, M.G.B. Drew, M. Estrader, C. Diaz, A. Ghosh, Polyhedron 27 (2008, ) 2625.

[54] (a) I.A. Koval, M. Sgobba, M. Huisman, M. Lüken, E. Saint-Aman, P. Gamez, B. Krebs, J. Reedijk, Inorg. Chim. Acta 359 (2006) 4071; (b) C.P. Pradeep, S.K. Das, 
Polyhedron 28 (2009) 630; (c) S. Thakurta, P. Roy, G. Rosair, C.J. Gómez-García, E. Garribba, S. Mitra, Polyhedron 28 (2009) 695.

[55] A. Trujillo, F. Justaud, L. Toupet, O. Cador, D. Carrillo, C. Manzur, J.-R. Hamon, New J. Chem. 35 (2011) 2027.

[56] B. Bleaney, K. D. Bowers, Proc. Roy. Soc. London, A 214 (1952) 451.

[57] J.-P. Malrieu, R. Caballol, C.J. Calzado, C. de Graaf, N. Guihéry, Chem. Rev. 114 (2014) 429.

[58] (a) B. Le Guennic, N. Ben Amor, D. Maynau, V. Robert, J. Chem. Theory Comput. 5 (2009) 1506; (b) J. S. Costa, N.A.G. Bandeira, B. Le Guennic, V. Robert, P. Gamez, G. Chastanet, L. Ortiz-Frade, L. Gasque, Inorg. Chem. 50 (2011) 5696; (c) B. Kozlevcar, N. Kitanovski, Z. Jaglicic, N.A.G. Bandeira, V. Robert, B. Le Guennic, P. Gamez, Inorg. Chem. 51 (2012) 3094; (d) N.A.G. Bandeira, D. Maynau, V. Robert, B. Le Guennic, Inorg. Chem. 52 (2013) 7980.

[59] (a) I. de P.R. Moreira, F. Illas, Phys. Chem. Chem. Phys. 8 (2006) 1645; (b) A. Bencini, Inorg. Chim. Acta 361 (2008) 3820; (c) A. Bencini, F. Totti, J. Chem. Theory Comput. 5 (2009) 144; (d) F. Neese, Coord. Chem. Rev. 253 (2009) 526; (e) C.J. Cramer, D.G. Truhlar, Phys. Chem. Chem. Phys. 11 (2009) 10757; (f) A.J. Cohen, P. Mori-Sánchez, W. Yang, Chem. Rev. 112 (2012) 289. 